\title{
Determinação de pH e atividade de água (Aa) e sua inter-relação com o perfil bacteriológico de salsichas tipo "hot dog" comercializadas nos municípios do Rio de Janeiro e Niterói - RJ
}

\section{Determination of $\mathrm{pH}$ and activity water (aw) and relation between the with the bacteriological profile the samples bovine and chicken "hot dog" sausages that are vacuumed and retail commercialized and comes from supermarkets in Rio de Janeiro and Niterói - RJ}

\author{
Lucimar Lima Martins, ${ }^{*}$ lacir Francisco dos Santos, ${ }^{* *}$ Robson Maia Franco, ${ }^{* *}$ Luiz Antônio Trindade de Oliveira, ${ }^{* *}$ \\ Juliana Bezz***
}

\begin{abstract}
Resumo
Foram analisadas 100 amostras de salsichas tipo "hot dog" comercializadas em embalagens a vácuo ( $\mathrm{n}=50$ ) e a granel $(n=50)$ em supermercados nos municípios de Niterói e Rio de Janeiro - RJ, sendo determinadas a atividade de água (Aa), $\mathrm{pH}$ e perfil bacteriológico (enumeração de coliformes a $35^{\circ} \mathrm{C}$ e termotolerantes; contagem de Staphylococcus coagulase positiva; contagem de Clostridium spp. sulfito redutores a $46^{\circ} \mathrm{C}$ e isolamento e identificação de Salmonella spp.). A Aa apresentou o valor médio de $0,8758,0 \mathrm{pH}$ apresentou valor médio de 6,08. De acordo com a legislação em vigor, $33 \%$ das amostras foram consideradas impróprias ao consumo, onde foram isolados todos os micro-organismos pesquisados. As salsichas tipo "hot dog" avaliadas representam riscos à saúde coletiva. Em relação à Aa foi observado crescimento de microorganismos em valores inferiores àqueles descritos na literatura para Aa.
\end{abstract}

Palavras-chave: salsichas, micro-organismos, atividade de água.

\begin{abstract}
Water activity - Aw, pH and bacteriological profile were assessed in 100 bovine and chicken "hot dog" sausages that are vacuumed and retail commercialized and comes from supermarkets in Rio de Janeiro and Niteroi-RJ. Water activity measures showed a mean value of 0,8758 , and $\mathrm{pH}$ measures showed a mean value of 6,08 . The samples were submitted to the following bacteriological analysis: coliforms at $35^{\circ} \mathrm{C}$ and $45^{\circ} \mathrm{C}$ enumeration, and Escherichia coli; Staphylococcus spp. coagulase positive counting; Clostridium sulfito reductors at $46^{\circ} \mathrm{C}$ and Clostridium perfringens counting and Salmonella spp. research. The utilized methodology was traditional with appropriate modifications. By comparing the achieved results with the current legislation we could see that $33 \%$ of the sample was considered inappropriate to consume, with the isolation of every microorganism researched. According to these results, we can conclude that the "hot dog" sausages may cause foodborne illness, representing a huge risk to people's health. About aw, we could observe the microorganism growth in smaller values than the ones described by the literature.
\end{abstract}

Keywords: sausages, microorganism, activity water.

\section{Introdução}

A atividade de água ( $\mathrm{Aa})$, o pH e a composição química do alimento são fatores que determinam o tipo de deterioração microbiana no produto. O limite máximo de água disponível para o desenvolvimiento microbiano é condicionado pelo Aa do alimento. O limite mais baixo para o crescimento de microorganismos nos alimentos está em torno de $\mathrm{Aa} 0,60$. Na escala entre um e 0,60 de Aa, um grande número de microorganismos podem crescer, dentre eles alguns patógenos (Rahman et al., 2004).

A determinação da Aa em diversos países é adotada como "standards" compulsórios baseados nos valores de Aa admissíveis, onde as medidas de manutenção da qualidade do alimento são estabelecidas a partir desta análise.

\footnotetext{
* Mestranda em Higiene Veterinária e Processamento Tecnológico de POA, bolsista CAPES/UFF. Rua Alfredo Thulke, 436/201 - Bairro Bela Vista Erechim/RS, CEP 99700-000 - lucilimartins@yahoo.com.br ou lucimar-martins@seapa.rs.gov.br. Tels: 54-35227111 / 54-33414308 / 54-91051797. Autor para correspondência.

** Professores do Departamento de Tecnologia de Alimentos - MTA/UFF.

*** Acadêmica em Medicina Veterinária UFF.
} 
Os micro-organismos Gram-negativos que ocorrem nos processos de deterioração são particularmente mais sensíveis à diminuição da $\mathrm{Aa}$, e destes a maioria das enterobactérias paralisam sua multiplicação em $\mathrm{Aa}$ abaixo de 0,95 . Porém, as bactérias Gram-positivas são mais resistente às baixas atividade de água e a resistência do Staphylococcus aureus torna-se particularmente perigosa (Nissen e Holck, 1998; Pardi et al., 2001).

Como a aplicação da medida de Aa está relacionada com o controle do crescimento microbiano, este estudo objetivou avaliar a inter-relação entre os valores de $\mathrm{Aa}$ e $\mathrm{O} \mathrm{pH}$ das amostras analisadas com o perfil bacteriológico.
A análise estatística dos dados de $\mathrm{pH}$ e $\mathrm{Aa}$ foi determinada pela média aritmética, variações entre as médias, adotandose a análise da variância para os dados de $\mathrm{pH}$ e Aa; os dados das análises bacteriológicas foram analisados segundo o critério de ocorrência ou não ocorrência (Rodrigues, 1993).

\section{Resultados}

Os resultados das análises bacteriológicas foram comparados com os padrões estabelecidos pela Resolução RDC ํo 12, de 2 de janeiro de 2001 (Brasil, 2001) e podem ser visualizados na Tabela 1.

\section{Material e métodos}

Um total de 100 amostras de salsichas "hot dog" de carne bovina (tipo tradicional $\mathrm{n}=50$ ) e de frango (tipo frango $n=50$ ) comercializadas em embalagem a vácuo $(n=25$ para cada tipo) e a granel ( $n=25$ para cada tipo) foram obtidas de forma aleatória em estabelecimentos comerciais varejistas localizadas nos municípios do Rio de Janeiro e de Niterói - RJ. A obtenção das amostras obedeceu às especificações da Resolução no 12 , de 2 de janeiro de 2001 (Brasil, 2001), sendo procedida da seguinte forma: as amostras comercializadas em embalagens a vácuo foram obtidas em suas embalagens originais não violadas nos balcões frigoríficos dos supermercados, e as amostras a granel foram solicitadas nos balcões de pesagem (açou-gues) em embalagens fornecidas pelo estabelecimento comercial, observando a quantidade mínima de 500 gramas por unidade amostral. Todas as amostras estavam dentro do prazo de validade e com temperatura de exposição de acordo com as normas técnicas para embutidos resfriados. Foram enviadas ao laboratório devidamente identificadas e em condições adequadas para a análise sendo transpor-tadas em caixas isotérmicas, com gelo, e mantidas sob refri-geração. $O$ processo de análise foi iniciado sempre no mes-mo dia de obtenção das amostras, procedendo-se então às primeiras etapas dos testes bacteriológicos, dando segui-mento às análises físico-químicas. As amostras procediam de estabelecimentos sob inspeção federal, de diferentes empresas.

As análises bacteriológicas foram realizadas, no Laboratório de Controle Microbiológico de Faculdade de Veterinária da Universidade Federal Fluminense - UFF, segundo determinações da RDC no 12, de 2 de janeiro de 2001 (Brasil, 2001) e com base nas técnicas descritas pelo Laboratório Nacional de Referência Animal - LANARA (Brasil, 2003).

Para determinação do $\mathrm{pH}$ foi utilizada a metodologia com base nas técnicas descritas pelo LANARA (Brasil, 1981).

Para determinação da atividade de água $(\mathrm{Aa})$ foi utilizado o aparelho Pawkit Decagon $\AA$. A preparação da amostra e a utilização do aparelho foram realizadas conforme instruções descritas no manual de operação.
Os resultados das análises bacteriológicas quando analisados estatisticamente, não apresentaram diferenças estatísticas significativas.

Em 17/100 amostras de salsichas "hot dog" a presença de coliformes termotolerantes foi verificada em NMP de coliformes a $45^{\circ} \mathrm{C}$ que ultrapassaram os limites estabelecidos por lei em 16/17 amostras positivas. Em relação à ocorrência de coliformes a $45^{\circ} \mathrm{C}$, constatou-se que as amostras de salsichas "hot dog" tipo tradicional e tipo frango comercializadas em embalagens a vácuo comportaram-se de maneira semelhante: ambas tiveram $12 \%$ das amostras com valores acima do limite estabelecido por lei. Entretanto, as amostras de salsichas "hot dog" tipo tradicional e tipo frango comercializadas a granel apresentaram percentagens de ocorrência bem diferenciadas, onde apenas $4 \%$ das amostras tipo tradicional ultrapassaram os limites estabelecidos. Em contrapartida, $40 \%$ das salsichas tipo frango foram positivas, sendo que em $36 \%$ foram encontrados coliformes a $45^{\circ}$ acima dos limites estabelecidos.

Assim, estas amostras podem ser enquadradas como produtos processados ou mantidos em condições higiênicas insatisfatórias, muito embora a ocorrência de coliformes termotolerantes tenha sido bastante variável. Possivelmente, essas variações estão associadas ao fato de as amostras procederem de diferentes origens e estocadas em diferentes condições.

Com relação à contagem de Staphylococcus spp. coagulase positiva 37/100 amostras de salsichas "hot dog" foram positivas, 21 amostras encontravam-se acima do limite 
máximo estabelecido por lei, apresentando-se, portanto, fora dos limites de tolerância aceitáveis e classificadas como em condições higiênicas insatisfatórias.

As salsichas "hot dog" tipo frango apresentaram maior número de amostras positivas para Staphylococcus spp. coagulase positiva, onde $44 \%$ das amostras de salsichas "hot dog" tipo frango comercializadas em embalagem a vácuo e $60 \%$ das comercializadas a granel foram positivas. Contudo, as amostras de salsichas "hot dog" tipo tradicional comercializadas em embalagem a vácuo e a granel tiveram $20 \%$ e $32 \%$ de positividade para Staphylococcus spp. coagulase positiva, respectivamente. De acordo com Cunha Neto et al. (2002), a presença de Staphylococcus spp. coagulase positiva indica a possível presença de enterotoxina; entretanto, a ausência ou presença de pequeno número deste micro-organismo, sobretudo em alimentos processados submetidos ao tratamento térmico, não determina que estes produtos não possam ocasionar intoxicação alimentar.

Nesta pesquisa ocorreu o crescimento de Clostridium spp. sulfito redutores a $46^{\circ} \mathrm{C} /$ Clostridium perfringens em cinco das 50 amostras (10\%) de salsichas "hot dog" comercializadas a granel, nas quais as contagens ultrapassaram o limite de tolerância aceitável, classificando-as como amostras em condições higênico-sanitárias insatisfatórias e, portanto, potenciais veículos de intoxicação alimentar. Sendo uma amostra tipo tradicional (4\%) e quatro amostras (16\%) tipo frango comercializadas a granel.

Os padrões legais determinam a ausência de Salmonella spp. para qualquer tipo de produto alimentício. Nesta pesquisa detectou-se a presença de Salmonella spp. em três das 50 amostras $(6 \%)$ de salsichas "hot dog" comercializadas a granel. Sendo uma amostra tipo tradicional (4\%) e duas amostras (8\%) tipo frango. Desta forma, estas amostras foram consideradas impróprias para o consumo, pois são passíveis de causarem graves surtos de infecções alimentares.

Não ocorreram amostras positivas na contagem de Clostridium spp. sulfito redutores a $46^{\circ} \mathrm{C} /$ Clostridium perfringens e pesquisa de Salmonella ssp. nas amostras de salsichas "hot dog" comercializadas em embalagens a vácuo de ambos os tipos (tradicional x frango).

Os dados de $\mathrm{pH}$ das amostras de salsichas "hot dog" mostraram efeito significativo $(P<0,01)$ para os tipos de embalagens. $\mathrm{O} \mathrm{pH}$ das salsichas "hot dog" comercializadas em embalagem a vácuo, independentemente dos tipos, têm em média de $\mathrm{pH}$ igual a 6,27 , que foi superior ao $\mathrm{pH}$ médio de 5,90 das salsichas "hot dog" comercializadas a granel (Tabela 2).

Os dados de Aa das amostras de salsichas "hot dog" (Tabela 4), revelaram que não houve efeito significativo para os tipos de embalagens $(P>0,05)$, mas houve efeito significativo para os tipos de salsichas e a interação embalagens versus tipos. Assim, optou-se por fazer novo desmembramento da soma de quadrados de tratamentos (Tabela 4.1), onde verificou-se efeito significativo entre tipos de salsichas $(P<0,05)$. A média de Aa $(0,8850)$ das salsichas "hot dog" tipo frango foi superior a média de Aa $(0,8666)$ das salsichas "hot dog" tipo tradicional (Tabela 3).
Tabela 2: Médias de pH das amostras de salsichas "hot dog", segundo os tipos de salsichas e embalagens

\begin{tabular}{l|c|c|c}
\hline Tipos & Vácuo & Granel & Média/tipo \\
\hline Tradicional & 6,19 & 5,89 & 6,04 \\
\hline Frango & 6,34 & 5,91 & 6,12 \\
\hline Média/embalagem & 6,27 & 5,90 & 6,08 \\
\hline
\end{tabular}

Tabela 3: Médias de Aa das amostras de salsichas "hot dog", segundo os tipos de salsichas e embalagens

\begin{tabular}{l|c|c|c}
\hline Tipos & Vácuo & Granel & Média/tipo \\
\hline Tradicional & 0,8792 & 0,8540 & 0,8666 \\
\hline Frango & 0,8752 & 0,8948 & 0,8850 \\
\hline Média/embalagem & 0,8772 & 0,8744 & 0,8758 \\
\hline
\end{tabular}

Tabela 4: Análise da variância dos valores de Aa das amostras de salsichas "hot dog", segundo os tipos de salsichas e embalagens

\begin{tabular}{l|c|c|c|c}
\hline \multicolumn{1}{c|}{ Fontes de Variação } & $\mathrm{GL}$ & $\mathrm{SQ}$ & $\mathrm{QM}$ & $\mathrm{F}$ \\
\hline Total & 99 & 0,1676 & & \\
\hline Embalagens (vácuo $\times$ granel) & 1 & 0,0002 & 0,0002 & - \\
\hline Tipos (tradicional $\times$ frango) & 1 & 0,0085 & 0,0085 & $5,67^{*}$ \\
\hline Embalagens $\times$ tipos & 1 & 0,0125 & 0,0125 & $8,33^{* *}$ \\
\hline Erro & 96 & 0,1464 & 0,0015 & \\
\hline
\end{tabular}

Nota: - não significativo a $5 \%$ de probabilidade $(p>0,05)$

$\left.{ }^{*}\right)$ significativo a $5 \%$ de probabilidade $(p<0,05)$

$\left({ }^{* *}\right)$ significativo a $1 \%$ de probabilidade $(p<0,01)$

Tabela 4.1: Análise da variância dos valores de Aa das amostras de salsichas "hot dog', segundo os tipos de salsichas e embalagens, com novo desdobramento da soma de quadrados de tratamentos

\begin{tabular}{l|c|c|c|c}
\hline \multicolumn{1}{c|}{ Fontes de Variação } & GL & SQ & QM & $\mathrm{F}$ \\
\hline Total & 99 & 0,1676 & & \\
\hline Tipos (tradicional x frango) & 1 & 0,0085 & 0,0085 & $5,67^{*}$ \\
\hline Embalagens d. tradicional & 1 & 0,0079 & 0,0079 & $5,27^{*}$ \\
\hline Embalagens d. frango & 1 & 0,0048 & 0,0048 & $3,20 \mathrm{~ns}$ \\
\hline Erro & 96 & 0,1464 & 0,0015 & \\
\hline
\end{tabular}

Nota: ns não significativo a $5 \%$ de probabilidade $(p>0,05)$

$\left(^{*}\right)$ significativo a $5 \%$ de probabilidade $(p<0,05)$

\section{Discussão}

Neste estudo, os valores médios de $\mathrm{pH}$ variaram bastante. $\mathrm{O} \mathrm{pH}$ das amostras de salsichas "hot dog" comercializadas em embalagens a vácuo $(6,27)$ foi superior ao $\mathrm{pH}(5,90)$ das amostras comercializadas a granel. $\mathrm{O}$ menor valor de $\mathrm{pH}$ 
das amostras a granel pode ser justificado pelo maior crescimento microbiano somado ao fato da exposição ao oxigênio (aeração), que promove melhores condições de crescimento aos micro-organismos (Adams e Moss, 1997). Além disso, a ocorrência de pH baixo pode ser justificado pelo desenvolvimento das bactérias ácido-lácticas, não pesquisadas neste estudo.

Outros fatores como temperatura, atividade de água e natureza do acidulante utilizado na formulação do produto interferem diretamente nos valores de $\mathrm{pH}$. Neste estudo, os valores de $\mathrm{pH}$ encontrados foram adequados ao crescimento dos micro-organismos pesquisados.

As variações médias de Aa foram de 0,8540 a 0,8948 (Tabela 3 e 4). Segundo Cunha Neto et al. (2002), a maior Aa das salsichas "hot dog " tipo frango deriva da sua composição, onde a incorporação de carne mecanicamente separada e polifosfatos resultam num produto com maior suculência e maciez, e também com maior conteúdo de água que favorece o desenvolvimento microbiano, conforme explicitam os resultados deste estudo.

Analisando-se os resultados deste estudo, verificou-se que as médias de Aa encontram-se na faixa de 0,86 a 0,90; contudo, observou-se o crescimento de micro-organismo em Aa inferiores às descritas na literatura como mínimas para o crescimento da microbiota isolada. Em geral, as bactérias Gram-negativas necessitam de maiores valores de Aa para o crescimento do que as Gram-positivas. Nos resultados deste estudo registrou-se Aa mínima para Gram-negativas (coliformes) de 0,79 e 0,80 e, para Gram-positivas Staphylococcus spp. coagulase positiva, de 0,75 e 0,77 e Clostridium perfringens de 0,87 a 0,91.

Em relação aos coliformes termotolerantes, o nível de Aa para o crescimento reportado pela maioria dos autores é de 0,95 . Contudo, estudos referentes à sobrevivência destes micro-organismos em condições experimentais chegam a observar o crescimento em atividade de até 0,68, o que evidencia a possibilidade de crescimento nos valores de Aa encontrados neste estudo.

Já os $S$. aureus, de acordo com a literatura, crescem e produzem enterotoxinas em Aa de até 0,86; contudo, seu crescimento já foi demonstrado em valores de Aa abaixo de 0,83 . No presente estudo não foram realizadas análises para verificação da produção de enterotoxinas, porém detectouse o crescimento de Staphylococcus spp. coagulase positiva em valores de $\mathrm{Aa}$ de 0,75 , o que sugere sua potencialidade para produção de enterotoxinas.

$\mathrm{O} \mathrm{Cl}$. Perfringens na presença de $\mathrm{NaCl}$ tem como limite mínimo de Aa de 0,95 a 0,96, variando de acordo com o umectante presente no produto analisado, sendo importante ressaltar que os valores de Aa estão diretamente relacionados com o pH e a temperatura. Pode-se, portanto considerar tal interação responsável pelo crescimento de $\mathrm{Cl}$. Perfringens em Aa de 0,87 a 0,91.

Como a Aa média da maioria das amostras de salsichas "hot dog" encontrou-se numa faixa descrita como desfavorável ao desenvolvimento de micro-organismos patogênicos, justifica-se a ausência de crescimento dos micro-organismos pesquisados em $47 \%$ das amostras analisadas.

\section{Conclusões}

- A avaliação do perfil bacteriológico das salsichas tipo "hot dog" tipo tradicional e de frango comercializadas no mercado varejista nos municípios do Rio de Janeiro e Niterói $\mathrm{RJ}$, frente à presença potencial de patógenos enquadram estes alimentos como veículos potenciais de Enfermidades Transmitidas por Alimentos (ETA), o que implica a aplicação de medidas preventivas: como uma atuação mais contundente dos órgãos fiscalizadores aos estabelecimentos que processam e comercializam produtos de origem animal e que a educação sanitária seja vista como medida imperativa para assegurar a qualidade dos alimentos, para que a aplicação das Boas Práticas de Fabricação (BPF) e os princípios da Análise de Perigos e Pontos Críticos de Controle sejam realmente efetivos;

- As amostras de salsichas "hot dog" tipo frango, em especial as comercializadas a granel, apresentaram maior prevalência dos micro-organismos pesquisados, tendo como prerrogativas para este resultado os seguintes fatores: tais amostras apresentaram maior $\mathrm{Aa}$, o que favorece o crescimento microbiano. Outro fator importante a ser considerado é a comercialização de produtos a granel, onde o armazenamento de produtos cárneos em contato com oxigênio origina um potencial redox na superfície dos mesmos, apropriado ao desenvolvimento de micro-organismos aeróbios, somado ao fato do perigo da manipulação inadequada e a maior possibilidade de contaminação cruzada;

- Constataram-se variações de capacidade de crescimento dos micro-organismos pesquisados quanto aos valores de Aa descritos na literatura, o que torna importante o desenvolvimento de estudos relativos às diferentes interações entre os parâmetros de $\mathrm{pH}, \mathrm{Aa}$, composição química, temperatura e potencial de oxirredução, pois o crescimento dos micro-organismos resulta da interação destes fatores.

\section{Agradecimentos}

À CAPES, pelo apoio financeiro, e aos professores do Programa de Pós-graduação em Medicina Veterinária UFF pelo apoio e incentivo científico.

\section{Referências}

ADAMS, M. R.; MOSS, M. O. Microbiología de los alimentos. Espanha: Editorial Acribia, 1997. 464 p.
BRASIL. Ministério da Agricultura, Pecuária e do Abastecimento. Instrução Normativa no 62 , de 26 de agosto de 2003. Oficializa os Métodos Analíticos Oficiais para controle de Produtos de Origem Animal e Água. Diário Oficial da República Federativa do Brasil, Brasília, DF, p. 14, 18 set. 2003. Seção 1. 
BRASIL. Ministério da Saúde. Resolução RDC nํ12, de 2 de janeiro de 2001. Aprova o Regulamento Técnico sobre Padrões Microbiológicos para Alimentos. Diário Oficial da República Federativa do Brasil, Brasília, DF, n. 7 - E, p. 45-53, de 10 de janeiro de 2001. Seção 1.

BRASIL. Ministério da Agricultura, Pecuária e do Abastecimento. Secretaria Nacional de Defesa Agropecuária. Laboratório Nacional de Referência Animal - LANARA. Métodos Analíticos Oficiais para o Controle de Produtos de Origem Animal e seus Ingredientes. Métodos Físico-Químicos. Brasília, DF, 1981.

CUNHA NETO, A.; SILVA, C. G. M..; STAMFORD, T. L. M. Staphylococcus enterotoxigênicos em alimentos in natura e processados no estado de Pernambuco, Brasil. Ciência e Tecnologia de Alimentos, v. 22, n. 3, p. 263-271, set.-dez., 2002.
NISSEN, H.; HOLCK, A. Survival of Escherichia coliO157:H7, Listeria monicytogenes and Salmonella Kentucky in Norwegian fermented, dry sausage. Food Microbiology, v. 15, p. 273-279, 1998.

PARDI, M. C.; SANTOS, I. F.; SOUZA, E. R.; PARDI, H. S. Ciência e Tecnologia da Carne. 2. ed. Goiânia: Editora da UFG, 2001. 2 v.

RAHMAN, M. S.; GUIZANI, N. G.; AL-RUZEIKI, M. H. D- and Z-values of microflora in tuna mince during moist and dry heating. LebensmittelWissenschaft und Technologie, v. 37, p. 93-98, 2004.

RODRIGUES, P. C. Bioestatística. 2. ed. Niterói: EdUFF, 1993. 268 p. 